\title{
Public awareness, knowledge and sensitivity towards celiac disease and gluten-free diet is insufficient: a survey from Turkey
}

\author{
Bilge TAŞKIN ${ }^{1 *}$ (D), Nazlı SAVLAK ${ }^{1}$
}

\begin{abstract}
One of the most challenging aspects of celiac disease management is lack of awareness in public. Aim of the study was to evaluate public awareness and sensitivity on celiac disease and gluten-free diet. 501 individuals in Manisa, Turkey were subjected to a survey to obtain information on demographics, awareness of celiac disease, celiac and gluten-free diet relationship, effect on social life quality and social awareness and sensitivity. Results were analyzed by chi-square test. $43.9 \%$ of the public had never heard of celiac disease before. Females were more aware of the disease and gluten-free diet dependency. Majority of the postgraduates $(79.6 \%)$ recognized the disease. $44.9 \%$ of the respondents remarked that celiac patients had hesitations on dining out, while $32.3 \%$ found those people restricted for travel and holiday activities. Above one-third of subjects indicated that gluten-free product variety in the market was inadequate. However, more than half had no idea on these. Over $50 \%$ felt that, social awareness and sensitivity towards disease was unsatisfactory. This study was conducted to mirror the society's approach towards celiac patients. It was demonstrated that public's awareness and sensitivity about celiac disease was scarce. Knowledge of 'celiac' needs to be raised.
\end{abstract}

Keywords: celiac, gluten-free diet, knowledge, public awareness, sensitivity, survey.

Practical Application: Knowledge of celiac needs to be raised. This study mirrored social restrictions on celiacs and it may promote to design and conduct educational programs on $\mathrm{CD}$ management.

\section{Introduction}

Celiac disease $(\mathrm{CD})$ is an immune-mediated disorder triggered by dietary gluten in genetically susceptible people consuming cereals; wheat, barley, rye and sometimes oat (Fasano \& Catassi, 2012). Being a life-long disorder; if untreated, it is associated with increased morbidity and mortality (Gujral et al., 2012). Moreover, gluten-free diet (GFD) has become a global concern recently not only to the celiac patients but also to some consumers who wonders to eat healthy foods (Alvarez-Jubete et al., 2010). The disease is known to be universal affecting people of any age and racial groups with an estimated average prevalence of $1-2 \%$ in the general population (Rodrigo, 2006). Point is that; frequency is increasing in several developing countries as a result of westernization of the diet, dietarial alteration due to agricultural revolution, changes in wheat production and preparation, raised awareness and diagnosis of the disease (Rostami et al., 2004; Fasano \& Catassi, 2012).

Although frequency of CD reported as approximately $0.3-1.0 \%$ in Turkey; the exact overall prevalence is not known yet (Turkey, 2019). Since only $10 \%$ of the people having the disorder has been clinically diagnosed (Turkey, 2019); the real number of individuals embracing a gluten-free diet is expected to be much more than those reported. As known; the low frequencies of $\mathrm{CD}$ and delays of diagnosis in developing countries were likely due to low levels of awareness. Delays in diagnosis can lead to serious complications such as osteoporosis and small intestinal lymphoma (Collin et al., 1994), neurologic disorders, impaired splenic function, ulcerative jejunitis, infertility and cancer (Fasano \& Catassi, 2001). Today, detection of the disease can be upgraded with the faster and easier diagnostic techniques. However; before that, one of the most compelling aspects of celiac disease management is that the lack of awareness in the public. Improved awareness of celiac disease may lead to earlier diagnosis and lower risk of various relevant complications.

In spite of some researches that have been conducted on knowledge of chefs, physicians and awareness/perception of public regarding celiac disease and GF diet (Zipser et al., 2005; Aziz et al., 2014; Golley et al., 2015; Schultz et al., 2017), number of studies on celiac disease awareness across the world is not adequate. Celiac people frequently feel asocial and depressed as their friends and even their family do not emphatize with them. Being understood and adopted by the society is worthy for their social and psychological well-being. Therefore, present study aims to fill this gap by surveying awareness of general public in order to mirror the social restrictions of celiacs.

\section{Materials and methods}

\subsection{Study design and population}

Awareness of celiac disease and gluten-free diet was determined with a face-to-face conversation questionnaire which was performed with individuals in city centrum of Manisa, Turkey at the year 2017. All of the participants were volunteer. 
Probability sampling method was used and the sample size was determined by Equation 1 below (Krejcie \& Morgan, 1970);

$n=\left[X^{2} N P(1-P)\right] /\left[d^{2}(N-1)+X^{2} P(1-P)\right]$

Where; $\mathrm{n}=$ required sample size; $\mathrm{N}=$ population size; $\mathrm{X}^{2}=$ the value of chi-square for 1 degree of freedom at the desired confidence level; $\mathrm{P}=$ population proportion (assumed to be 0.50 since this would provide the maximum sample size); $\mathrm{d}=$ degree of accuracy expressed as a proportion (0.05).

According to Manisa Governorship Report (Manisa Governorship, 2016); Manisa city center population is 390,182 . $\mathrm{X}^{2}$ value for $\alpha=0.05$ at $95 \%$ confidence level equals to $1.96^{2}=3.84$. Therefore, from the formula needed sample size is calculated by Equation 2 as below;

$n=\left[\begin{array}{l}3.84 \times 390182 \times 0.5 \times 0.5] /\left[\left(0.05^{2}\right) x\right. \\ (390182-1)+3.84 \times 0.5 \times(1-0.5)\end{array}\right]=383.62 \approx 384$

For increased reliability of the study, the survey was applied to 501 randomly selected public participants. Gender, age and education level were the independent variables in the study. Study involved participants from different sets of age and education level, and with a balanced number of men and women.

\subsection{Questionnaire}

The questionnaire contained 15 questions which were developed based on literature review on potentially similar topics of interest. Questions involved awareness of celiac disease (Q1), knowledge on risk factors of celiac disease, celiac disease and gluten-free diet relationship (Q2, Q3, Q10), effect of celiac on daily and social life quality (Q4, Q8, Q9), awareness and knowledge of gluten-free market (Q5, Q6, Q7, Q11, Q13, Q15), social awareness and sensitivity towards the disease (Q12, Q14).

\subsection{Statistical analysis}

For statistical analyses SPSS Statistics 22.0.0.0 Programme (IBM, Armonk, USA) was used. Chi-square test was used to determine differences between categorical variables. $p$ - values below 0.05 were considered as statistically significant. The study was approved by Manisa Celal Bayar University Science Ethics Committee.

\section{Results}

\subsection{Demographic characteristics}

Demographics of the study participants are given in Table 1. Of these participants; 266 were females (53.1\%), 235 were males (46.9\%) where $35.3 \%$ is between the ages of $19-25$ and $45.1 \%$ has an education degree of university (bachelor's). Table 2 shows the relationship between questions and age, gender, education level of those people. Among demographics; only education level was significantly associated $(p<0.05)$ with each of the questions addressed. Thus, it can be suggested that education can be considered as the most important determinant for celiac disease awareness, followed by gender.

\subsection{Awareness of celiac disease}

In order to determine the awareness of public towards celiac disease and GF diet, participants were firstly asked if they had ever heard of celiac disease (CD). "CD awareness" meant that the individual had heard of the disease before. Among participants $(\mathrm{n}=501) 50.9 \%$ had heard of celiac disease, $43.9 \%$ had never heard before and the rest stated no idea (Q1, Table 3). Increasing awareness level of public is key a factor in diagnosis and treatment of disease, and improvement of celiac individuals' life quality. Our finding is similar with those of the general public studies in UK (47\%, in 2005) (Karajeh et al., 2005) and USA (44.2\%, in 2011) (Simpson et al., 2011). However, in a UK study, a noticeable increase in the public's awareness regarding $\mathrm{CD}$ was ascertained from the years 2003 to 2013 , from $44.2 \%, \mathrm{n}=513$ to $74.4 \%, \mathrm{n}=575$ (Aziz et al., 2014). Thus, compared to this most recently reported study, our result regarding the awareness of $\mathrm{CD}$ seems unsatisfying. Britain is a developed country, whereas Turkey is still a developing country. Therefore, this may have caused the difference between the results. The unawareness in our study might be attributed to inadequacy of media coverage and training on $\mathrm{CD}$ in Turkey. Additionally, less concerns of Turkish consumers towards health issues related to GFD can be another possible factor.

Awareness of $\mathrm{CD}$ among women exceeds that of the men (57.5\% of women versus $43.4 \%$ of men had heard of CD, $p<0.009$ ). This may be because that the prevalence of the disease is more common among women. In a previous UK study, no significant difference was found comparing male chefs to female chefs on their knowledge of CD (Karajeh et al., 2005). A follow-up work of the authors in 2014 presented that increasing woman gender appeared to be associated with greater awareness of gluten related disorders (GRD) in general public (Aziz et al.,

Table 1. Demographic characteristics of the participants.

\begin{tabular}{lccc}
\hline $\begin{array}{c}\text { Demographic } \\
\text { Property }\end{array}$ & Group & Number & Frequency (\%) \\
\hline Age & $\leq 18$ & 47 & 9.4 \\
& $19-25$ & 177 & 35.3 \\
& $26-40$ & 133 & 26.5 \\
& $41-55$ & 100 & 20 \\
& $56-70$ & 36 & 7.2 \\
& $\geq 71$ & 8 & 1.6 \\
Gender & Total & 501 & 100 \\
& Female & 266 & 53.1 \\
Education level & Male & 235 & 46.9 \\
& Total & 501 & 100 \\
& Illiterate & 4 & 0.8 \\
& Literate & 21 & 4.2 \\
& Primary school & 77 & 15.4 \\
& High school & 119 & 23.8 \\
& Bachelor's & 226 & 45.1 \\
& Postgraduate & 54 & 10.8 \\
& Total & 501 & 100 \\
\hline
\end{tabular}


Table 2. Chi square $\mathrm{X}^{2}$ and $p$ values of the relation between demographical properties and survey questions.

\begin{tabular}{|c|c|c|c|c|c|c|}
\hline \multirow{2}{*}{ Questions } & \multicolumn{2}{|c|}{ Age } & \multicolumn{2}{|c|}{ Gender } & \multicolumn{2}{|c|}{ Education Level } \\
\hline & $X^{2}$ & ${ }^{*} p$ value & $X^{2}$ & ${ }^{*} p$ value & $X^{2}$ & ${ }^{*} p$ value \\
\hline Question 1 & 15.144 & 0.441 & 11.489 & 0.009 & 65.494 & 0.000 \\
\hline Question 2 & 13.277 & 0.209 & 8.410 & 0.015 & 56.651 & 0.000 \\
\hline Question 3 & 12.142 & 0.276 & 7.541 & 0.023 & 43.705 & 0.000 \\
\hline Question 4 & 6.311 & 0.788 & 8.599 & 0.014 & 35.706 & 0.000 \\
\hline Question 5 & 7.440 & 0.683 & 5.603 & 0.061 & 65.200 & 0.000 \\
\hline Question 6 & 20.498 & 0.154 & 2.169 & 0.538 & 35.901 & 0.002 \\
\hline Question 7 & 7.438 & 0.684 & 0.116 & 0.943 & 22.144 & 0.014 \\
\hline Question 8 & 21.33 & 0.019 & 13.001 & 0.002 & 61.942 & 0.000 \\
\hline Question 9 & 13.724 & 0.186 & 7.517 & 0.023 & 35.250 & 0.000 \\
\hline Question 10 & 9.822 & 0.456 & 12.957 & 0.002 & 42.271 & 0.000 \\
\hline Question 11 & 23.319 & 0.010 & 6.784 & 0.034 & 58.704 & 0.000 \\
\hline Question 12 & 17.456 & 0.065 & 4.940 & 0.085 & 22.137 & 0.014 \\
\hline Question 13 & 26.048 & 0.004 & 5.666 & 0.059 & 47.736 & 0.000 \\
\hline Question 14 & 26.765 & 0.003 & 7.172 & 0.028 & 59.136 & 0.000 \\
\hline Question 15 & 31.780 & 0.007 & 8.776 & 0.032 & 85.860 & 0.000 \\
\hline
\end{tabular}

${ }^{*} p$ value smaller than 0.05 is significant.

2014). Also Canadian authors found that female patients were significantly more knowledgeable respecting a gluten-free diet (Zarkadas et al., 2013).

As expected, a significant proportion of highly educated subjects (\%79.6, $\mathrm{n}=43$, postgraduate) was familiar with the disease. It was observed that illiterate people were less aware of the disease than the educated ones $(p=0.000)$. As reported in another study (Simpson et al., 2011), the trained chefs had more knowledge on disease than untrained ones; $83 \%$ compared to $52 \%$. In our study, as the percentage of the individuals that heard of $\mathrm{CD}$ reaches up to $79.6 \%$ in postgraduate level, we can reveal that the awareness of $\mathrm{CD}$ increased as the level of education increased. Probably, that may be explained by a paucity of education and omission in the press and mass media about this disorder at early stages of schools. Unexpectedly, no significant difference was observed regarding the awareness among the age groups of participants $(p=0.441)$.

\subsection{CDßGF diet relationship and risk factors of celiac disease}

A question was asked to assess the recognition of GF diet and CD relationship (Q2, Table 3). Only $42.5 \%$ of all participants affirmed that celiacs cannot consume gluten containing food products, whereas a significant percentage of the individuals (46.1\%) did not know that and even $11.4 \%$ had no idea. There was a significant difference between women ( $48.5 \%$ of women) and men ( $35.7 \%$ of men) on recognizing this relation ( $p=0.015$ ). On the other side; none of the illiterate individuals had this consciousness, but a vast majority of the postgraduates recognized this relationship (75.9\%) (Figure 1). Education increases the knowledge of epidemiology, diagnosis and treatment of the disease (Barzegar et al., 2017). Verifying this, in our study, as the level of education increased, so did this consciousness (Figure 1). Another research in the field signified the need for education among physicians, because only $35 \%$ of them had ever diagnosed CD (Zipser et al., 2005). However, although several

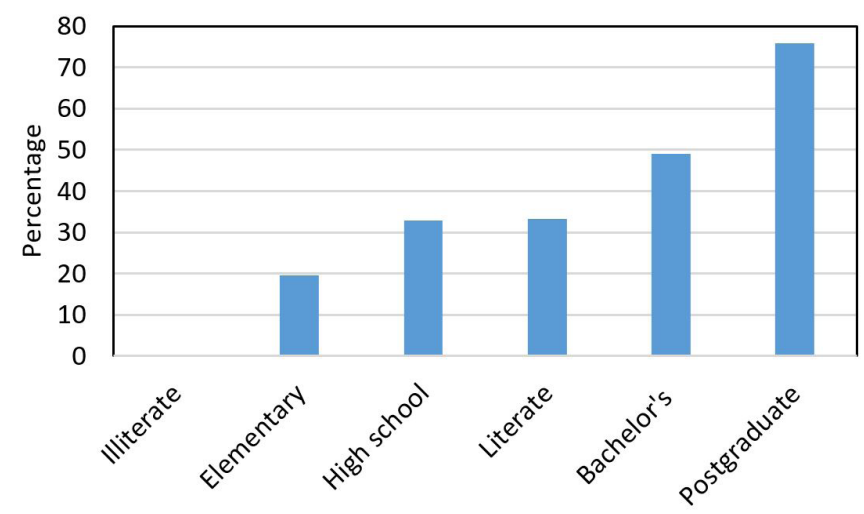

Figure 1. Percentage of the public that states to know the relationship between $\mathrm{CD}$ and gluten free diet.

studies (Zipser et al., 2005; Pham et al., 2014; Assiri et al., 2015) have proved that the general level of knowledge among trained physicians is still insufficient, this gap observed between illiterate and highly educated people was remarkable highlighting the importance of education level for social consciousness, in our study. Age was not significantly associated with Q2 $(p<0.05)$. This attitude of the surveyed group was confirmed with a cross question (Q10) querying if the individuals knew that the celiacs followed a special diet. The percentages of the answers given to this question were consistent with those given to Q2; where $41.9 \%$ of all indicated CD-GFD relation, $37.7 \%$ didn't know it and $20.4 \%$ had no idea. Likewise, $49.2 \%$ of women versus $33.6 \%$ of men ( $p=0.002)$ and most of the postgraduates $(72.2 \%)$ versus none of the illiterates $(p=0.000)$, affirmed this relationship. Thereby, the tendency was similar.

In a question which determines participants' knowledge on celiac risk factors (Q3), 18.8\% of participants (predominantly females) remarked that they knew the disease was not only genetically induced but could also occur in pregnancy, extreme stress and so on, whereas $49.5 \%$ of the subjects didn't know this 
Table 3. Public's responses to the survey questions assessing awareness and knowledge.

\begin{tabular}{|c|c|c|c|}
\hline Questions & Yes $[\mathrm{N}(\%)]$ & No $[N(\%)]$ & No idea $[N(\%)]$ \\
\hline Q1. Heard of $C D$ & $255(50.9)$ & $220(43.9)$ & $25(5.0)$ \\
\hline Q2. Celiacs cannot consume gluten-containing foods & $213(42.5)$ & $231(46.1)$ & $57(11.4)$ \\
\hline $\begin{array}{l}\text { Q3. CD is not only genetically induced but could also occur in cases of pregnancy, extreme stress } \\
\text { and etc. }\end{array}$ & $94(18.8)$ & $248(49.5)$ & $159(31.7)$ \\
\hline Q4. Activities of celiac patients such as travel and holidays are restricted & $162(32.3)$ & $134(26.7)$ & 205(40.9) \\
\hline Q5. GF products in the stores attracted my attention & $163(32.5)$ & $247(49.3)$ & $91(18.2)$ \\
\hline Q7. GF product servise extisted in retaurants and cafes around & $23(4.6)$ & $180(35.9)$ & 298(59.5) \\
\hline Q8. Celiac patients have hesitation and fears about dining out & 225(44.9) & $67(13.4)$ & $209(41.7)$ \\
\hline Q9. CD is an obstacle to socialization & $136(27.1)$ & $175(34.9)$ & $190(37.9)$ \\
\hline Q10. Celiacs follow a special diet & $210(41.9)$ & $189(37.7)$ & $102(20.4)$ \\
\hline Q11. Difficult to reach GF products for celiacs & $202(40.3)$ & $67(13.4)$ & $232(46.3)$ \\
\hline Q12. I think social sensitivity to $C D$ is enough & $29(5.8)$ & $271(54.1)$ & 201(40.1) \\
\hline Q13. Variety of the GF products in the market is enough & $16(3.2)$ & 193(38.5) & $292(58.3)$ \\
\hline Q14. I think social awareness to $C D$ is enough & $8(1.6)$ & $316(63.1)$ & $177(35.3)$ \\
\hline
\end{tabular}

$\mathrm{N}=$ Number of participants; $\mathrm{CD}=$ Celiac disease; $\mathrm{GF}=$ Gluten-free.

Table 4. Comparing the genders' awareness about socializing and dining-out.

\begin{tabular}{|c|c|c|c|c|c|}
\hline & Yes $[\mathrm{N}(\%)]$ & No $[\mathrm{N}(\%)]$ & No idea $[\mathrm{N}(\%)]$ & Chi square value & ${ }^{*} p$-value \\
\hline Q1. Ever heard of celiac disease & & & & 11.489 & 0.009 \\
\hline Female $(\mathrm{n}=266)$ & $153(57.5)$ & $102(38.3)$ & $10(3.8)$ & & \\
\hline Male $(\mathrm{n}=235)$ & $102(43.4)$ & $118(50.2)$ & $15(6.4)$ & & \\
\hline \multicolumn{4}{|c|}{ Q4. Activities of celiac patients such as travel and holidays are restricted } & 8.599 & 0.014 \\
\hline Female $(\mathrm{n}=266)$ & $99(37.2)$ & $73(27.4)$ & $94(35.3)$ & & \\
\hline Male $(\mathrm{n}=235)$ & $63(26.8)$ & $61(62.9)$ & $111(47.2)$ & & \\
\hline \multicolumn{4}{|c|}{ Q8. Celiac patients have hesitation and fears about dining out } & 13.001 & 0.002 \\
\hline Female $(\mathrm{n}=266)$ & $139(52.3)$ & $28(10.5)$ & $99(37.2)$ & & \\
\hline Male $(\mathrm{n}=235)$ & $86(36.6)$ & $39(16.6)$ & $110(46.8)$ & & \\
\hline \multicolumn{4}{|l|}{ Q9. $C D$ is an obstacle to socialization } & 7.517 & 0.023 \\
\hline Female $(\mathrm{n}=266)$ & $74(27.8)$ & $105(39.5)$ & $87(32.7)$ & & \\
\hline Male $(\mathrm{n}=235)$ & $62(26.4)$ & $70(29.8)$ & $103(43.8)$ & & \\
\hline
\end{tabular}

${ }^{*} p$ value smaller than 0.05 is significant; $\mathrm{N}=$ Number of participants; $\mathrm{n}=$ number of male and female participants; $\mathrm{CD}=$ Celiac disease.

information. $22.9 \%$ of women were more knowledgeable on this issue in response to $14.0 \%$ of men $(p<0.05)$. There was a noticeable significant difference between illiteral and postgraduated participants, respectively $0.0 \%$ and $35.2 \%(\mathrm{p}=0.000)$. This knowledge was not associated with the age scales $(p>0.05)$.

\subsection{Effect of celiac disease on daily and social life quality}

Adherence to GFD has negative effects on quality of life, especially in economic and social areas (Lee et al., 2007; Lee et al., 2012; Ciacci \& Zingone, 2015; Silvester et al., 2016). One of the most formidable aspect of a GFD is eating foods outside the home. $44.9 \%$ of the participants in this study think that celiac patients have fear and hesitations on dining out while, about one-third (32.3\%) find these individuals feel restricted for activities like travel and holidays. Besides, only $27.1 \%$ of them believe this disease is an obstacle to socialization (Q4, Q8, Q9, Table 3). Majority of the patients up to $82 \%$ (Karajeh et al., 2005) avoids dining out at restaurants, in addition some (38\%) avoids travelling (Zarkadas et al., 2006). According to one research; more than $50 \%$ of the parents of children with CD were reported to be concerned about social consequences of the diet due to life-long dietary restrictions in the future (Tomlin et al., 2015).

Predominantly women tended to be more sensitive and interested in the negative effects of $\mathrm{CD}$ on daily and social life. $52.3 \%$ of women versus $36.6 \%$ men $(p<0.002)$ agreed with the idea that celiacs mostly hesitated to eat outside (Q8, Table 4). Moreover, a greater proportion of women (37\%) than men $(27 \%)(p=0.014)$ feeled that celiac people are restricted during traveling and holiday like activities. A greater percentage of men than women (39.5\% versus $29.8 \%$, respectively, $p=0.023$ ) affirmed that celiac disorder hindered socializing. Majority of postgraduates (75.9\%) followed by half of the bachelor's (53.1\%) confirmed these hesitations of celiacs.

Effect of participants' age group was only significant while assessing dining out worries ( $p=0.019$, Table 2$)$. The most prominent age group thinking that celiacs might have fear and hesitations about eating outside were those between $19-25$ and $\geq 71$ (53.1 and 50\%, respectively). Not much amount of 18 aged and below individuals (23.4\%) agree with this idea, as well as, $57.4 \%$ of them having no idea (Q8). 
Highly educated individuals were significantly $(p=0.000)$ more aware of the limitations of celiacs on travel and holiday activities (Q4) and eating out (Q8). 57.4\% of postgraduates confirmed the restrictions of celiac people on travel like activities, while $75.9 \%$ of them confirmed hesitations of those celiac people on dining out. The answers to 'Is CD an obstacle to socialization?' question was also significantly related with education level $(p<0.05)$. Compared to literates (23.8\% of them), graduates of primary school $(20.8 \%$ of them), high school (23.5\% of them) and bachelor's $(28.8 \%$ of them); illiterates were more prone to see celiac disease as an obstacle to socialization (50.0\% of them) followed by postgraduates (37.0\% of them) (Q9). Surprising output of this survey was that; especially when compared to illiterates, from the point of educated individuals, it seemed easier to deal with socializing for celiacs.

\subsection{Awareness and knowledge of gluten-free market}

The gluten-free diet causes a compelling public health problem in the developing countries, particularly when commercial gluten-free products are not available. Public's attention on the existence of gluten-free products in markets (Q5) was not significantly associated with gender and age groups of participants $(p>0.05)$ but was directly significant with their education level $(p=0.000)$ (Table 2). At total, almost half of the subjects (49.3\%) were unaware of GF products, whereas only one -third of them (32.5\%) claimed they noticed, and remaining (18.2\%) did not have any idea about this issue (Table 3). Differing from other education categories, majority within postgraduates $(66.7 \%)$ and some of bachelor's (38.9\%) were familiar with GF products in the market. Not interestingly, illiterate $(0.0 \%)$ and primary school graduates (14.3\%) were unaware of their existence. Attention to these type of products in market was similar for men and women $(p>0.05)$.

Studies in the literature verified that gluten-free food products had a limited availability and were more expensive (up to 518\%) (Singh \& Whelan, 2011) than their gluten-containing counterparts in the market (Lee et al., 2007; Singh \& Whelan, 2011; Nascimento et al., 2014). Poor availability and elevated prices of these products can have a negative impact on the adherence to a GF diet. The high cost of packed gluten-free foods was specified by over $60 \%$ of the individuals with celiac as a difficulty experienced in their food purchases (Zarkadas et al., 2013). In our study, the participants were asked about prices of gluten-free products compared to standard (gluten-containing) ones in the market (Q6). Very few of public members (1.6\%) found gluten-free foods as cheaper than standard ones, or the same with them (4.8\%), but one- third found as more expensive (33.9\%). More than half (59.7\%) did not have any idea on the prices (Table 5). Among assessed demographics; only education level had a significant relationship $(\mathrm{p}<0.05)$ with public's opinion on gluten-free product prices. Gender and age groups were not related $(\mathrm{p}>0.05)$. Differently from other education levels, a greater amount of the postgraduates (50\%) and of bachelor's (42.5\%) described the GF products as expensive. Educated people can have more awareness and can do better benchmarking. However, only $14.3 \%$ of literates, $18.2 \%$ of primary school graduates, $24.4 \%$ of high school graduates and $25.0 \%$ of illiterates identified GF products as expensive. Relatively less portion of those highly educated people (bachelor's and postgraduates) answered as "no idea/ I don't know" but the vast majority of others (up to 85\%) had no idea on this.

It is well known that celiac patients are having moderate to high difficulty in reaching GF products (Rostami et al., 2004; Nascimento et al., 2014). Answers to the question 'Do you think that it is difficult to reach GF products for celiacs?' were significant for all of the independent variables $(p<0.05)(\mathrm{Q} 11)$. The proportion (40.3\%) of participants indicating that achieving a GF product is difficult (predominantly woman) was much greater than those who doesn't think likewise (13.6\%). Overall $46.3 \%$ had no idea (mostly aged $\leq 18$ ) (Table 3 ). The fact that young people at the age of 18 and below had no idea can be due to their lack of participation in home shopping and, of course, poorness of interest and consciousness. Women thought it was more difficult to reach gluten-free foods ( $60 \%$ of woman to $34.5 \%$ of men, $p<0.05$ ) probably because of being the most grocery shoppers in the household. Similarly, bachelor's and postgraduates reported that gluten-free foods were not easily accessible. Remaining of the education levels mostly didn't have any idea ( $75 \%$ of illiterates, $52.4 \%$ of literates, $64.9 \%$ of primary school and $62.2 \%$ of high school graduates) although some of them affirms that difficulty.

Participants' opinion regarding variety of gluten-free food products in the market was significantly associated with age groups and education level $(p<0.05)$, but no relationship was observed with gender $(p>0.05)$ (Q13). More than one-third of the participants (38.5\%) indicated that the variety of the GF products in the market was not enough, only a little amount (3.2\%) was satisfied, while most of them (58.3\%) had no idea. However, the majority of those who did not think variety was not adequate were adults between 19-25 ages (41.5\%) and bachelor's (58.0\%).

$44.5 \%$ of the participants described the GF food sector in Turkey as "underdeveloped" whereas $13 \%$ as "moderately developed" and $41.9 \%$ had no idea. The proportion of participants commenting as "high developed" was below 1\% (Q15) (Table 5). Statistically significant associations $(p<0.05)$ (Table 2) were determined between public's opinion on development level

Table 5. Public's responses to the survey questions assessing awareness and knowledge.

\begin{tabular}{|c|c|c|c|c|}
\hline Questions & Cheap $[\mathrm{N}(\%)]$ & Expensive $[\mathrm{N}(\%)]$ & The same $[\mathrm{N}(\%)]$ & No idea $[\mathrm{N}(\%)]$ \\
\hline \multirow[t]{2}{*}{ Q6. Price of GF products in the market } & $8(1.6)$ & $170(33.9)$ & $24(4.8)$ & $299(59.7)$ \\
\hline & $\begin{array}{c}\text { Under-developed } \\
{[\mathrm{N}(\%)]}\end{array}$ & $\begin{array}{l}\text { Developed } \\
{[\mathrm{N}(\%)]}\end{array}$ & $\begin{array}{c}\text { Moderately developed } \\
{[\mathrm{N}(\%)]}\end{array}$ & $\begin{array}{l}\text { No idea } \\
{[\mathrm{N}(\%)]}\end{array}$ \\
\hline Q15. Development of GF food sector in Turkey & $223(44.5)$ & $65(16.0)$ & $3(0.6)$ & $210(41.9)$ \\
\hline
\end{tabular}


and each of the demographical characteristics; gender, age and education. $49.6 \%$ of women versus $38.7 \%$ of men remarked this term as their closest view. The majority of those aged 71 years and older $(87.5 \%, \mathrm{n}=7)$, almost half of those between $19-25$ years $(55.4 \%, \mathrm{n}=98)$ and $56-70$ years $(47.2 \%, \mathrm{n}=17)$ designated it as "underdeveloped". In general; Turkey was described as "underdeveloped" on the production of gluten-free food. Interestingly; alongside the highly educated individuals and compared to literates/primary/high school graduates, a notable part of the illiterates (half of them) thought that this market was not developing enough. Those data imply that celiac awareness concerns all segments of society, not only educated classes.

\subsection{Social awareness and sensitivity}

More than half of the public feel that social awareness $(63.1 \%$, $\mathrm{n}=316)$ and sensitivity $(54.1 \%, \mathrm{n}=271)$ towards the disease is insufficient (Q12 and Q14) (Table 3). Unsatisfaction about the social awareness among men was less than that of women (57.0\% of man versus $68.4 \%$ of women unsatisfied, $p<0.028$ ). Majority of the postgraduates found the level of awareness $(85.2 \%$ of them, $p=0.000$ ) and sensitivity ( $66.7 \%$ of them, $p=0.014)$ of the society unsatisfactory.

Celiac people may need the society to understand them with an enhanced social awareness and to support them with information regarding their disease and the mandatory diet which is quite far away from conventional dietary habits. Public appears to care about social awareness and sensitivity on CD. More than half of the public feels that social awareness and sensitivity towards the disorder was unsatisfactory. Women were more interested in, and less satisfied with regard to the awareness of public compared to men. Those aged 18 and under were more likely to find general awareness as sufficient. Among education levels, prominently, literates together with educated ones over the bachelor's degree did not find the society sensitive and conscious to mentioned disorder. Increased awareness of CD in public would suggest that individuals suffering from gluten related disorders can feel more confident especially when they are out. This can bring the ease of socialization and improvement of their life quality.

\section{Conclusions}

Generally, celiac people feel asocial and depressed as their friends and family do not emphatize with them. Providing emotional and social support to celiac individuals is becoming an important requirement. This study showed that public's awareness, knowledge and sensitivity towards celiac disease was scarce in Turkey. Knowledge of 'celiac' needs to be raised. Further studies investigating needs of celiac patients relating to the awareness of CD and GF diet can be conducted.

\section{Acknowledgements}

This research did not receive any specific grant from funding agencies in the public, commercial, or not-for-profit sectors. The authors would like to thank to Manisa Celiac and Organic Nutrition Society for their support in developing survey questions.

\section{References}

Alvarez-Jubete, L., Arendt, E. K., \& Gallagher, E. (2010). Nutritive value of pseudocereals and their increasing use as functional gluten-free ingredients. Trends in Food Science \& Technology, 21(2), 106-113. http://dx.doi.org/10.1016/j.tifs.2009.10.014.

Assiri, A. M., Saeed, A., Saeed, E., El-Mouzan, M. I., Alsarkhy, A. A., Al-Turaiki, M., Al Mehaideb, A., Rashid, M., \& Ullah, A. (2015). Assessment of knowledge of celiac disease among health care professionals. Saudi Medical Journal, 36(6), 751-753. http://dx.doi. org/10.15537/smj.2015.6.11519. PMid:25987121.

Aziz, I., Karajeh, M. A., Zilkha, J., Tubman, E., Fowles, C., \& Sanders, D. S. (2014). Change in awareness of gluten-related disorders among chefs and the general public in the UK: a 10-year follow-up study. European Journal of Gastroenterology \& Hepatology, 26(11), 1228-1233. http://dx.doi.org/10.1097/MEG.0000000000000166. PMid:25144492.

Barzegar, F., Rostami-Nejad, M., Mohaghegh Shalmani, H., Sadeghi, A., Allahverdi Khani, M., \& Aldulaimi, D. (2017). The effect of education on the knowledge of patients with celiac disease. Gastroenterology and Hepatology from Bed To Bench, 10(4, Suppl 1), 15-19. PMid:29511466.

Ciacci, C., \& Zingone, F. (2015). The Perceived Social Burden in Celiac Disease. Diseases (Basel, Switzerland), 3(2), 102-110. http://dx.doi. org/10.3390/diseases3020102. PMid:28943612.

Collin, P., Reunala, T., Pukkala, E., Laippala, P., Keyriläinen, O., \& Pasternack, A. (1994). Coeliac disease - associated disorders and survival. Gut, 35(9), 1215-1218. http://dx.doi.org/10.1136/ gut.35.9.1215. PMid:7959226.

Fasano, A., \& Catassi, C. (2001). Current approaches to diagnosis and treatment of celiac disease: an evolving spectrum. Gastroenterology, 120(3), 636-651. http://dx.doi.org/10.1053/gast.2001.22123. PMid:11179241.

Fasano, A., \& Catassi, C. (2012). Celiac disease. The New England Journal of Medicine, 367(25), 2419-2426. http://dx.doi.org/10.1056/ NEJMcp1113994. PMid:23252527.

Golley, S., Corsini, N., Topping, D., Morell, M., \& Mohr, P. (2015). Motivations for avoiding wheat consumption in Australia: results from a population survey. Public Health Nutrition, 18(3), 490-499. http://dx.doi.org/10.1017/S1368980014000652. PMid:24739252.

Gujral, N., Freeman, H. J., \& Thomson, A. B. R. (2012). Celiac disease: prevalence, diagnosis, pathogenesis and treatment. World Journal of Gastroenterology, 18(42), 6036-6059. http://dx.doi.org/10.3748/ wjg.v18.i42.6036. PMid:23155333.

Karajeh, M. A., Hurlstone, D. P., Patel, T. M., \& Sanders, D. S. (2005). Chefs' knowledge of coeliac disease (compared to the public): a questionnaire survey from the United Kingdom. Clinical Nutrition (Edinburgh, Lothian), 24(2), 206-210. http://dx.doi.org/10.1016/j. clnu.2004.08.006. PMid:15784479.

Krejcie, R. V., \& Morgan, D. W. (1970). Determining and psychological measurement. Educational and Psychological Measurement, 30, 607-610.

Lee, A. R., Ng, D. L., Diamond, B., Ciaccio, E. J., \& Green, P. H. R. (2012). Living with coeliac disease: survey results from the USA. Journal of Human Nutrition and Dietetics, 25(3), 233-238. http://dx.doi.org/10.1111/j.1365-277X.2012.01236.x. PMid:22364496.

Lee, A. R., Ng, D. L., Zivin, J., \& Green, P. H. R. (2007). Economic burden of a gluten-free diet. Journal of Human Nutrition and Dietetics, 20(5), 423-430. http://dx.doi.org/10.1111/j.1365-277X.2007.00763.x. PMid:17845376. 
Manisa Governorship. (2016). Manisa province and districts population density distribution. Retrieved from http://www.manisa.gov.tr/ nufus-ve-dagilim

Nascimento, A. B., Fiates, G. M. R., Anjos, A., \& Teixeira, E. (2014). Gluten-free is not enough perception and suggestions of celiac consumers. International Journal of Food Sciences and Nutrition, 65(4), 394-398. http://dx.doi.org/10.3109/09637486.2013.879286 . PMid:24832676.

Pham, B. N., Musset, L., Chyderiotis, G., Olsson, N. O., \& Fabien, N. (2014). Celiac disease diagnosis: impact of guidelines on medical prescription in France. Journal of Digestive Diseases, 15(8), 435443. http://dx.doi.org/10.1111/1751-2980.12158. PMid:24825345.

Rodrigo, L. (2006). Celiac disease. World Journal of Gastroenterology, 12(41), 6585-6593. http://dx.doi.org/10.3748/wjg.v12.i41.6585. PMid:17075969.

Rostami, K., Malekzadeh, R., Shahbazkhani, B., Akbari, M. R., \& Catassi, C. (2004). Coeliac disease in Middle Eastern countries: A challenge for the evolutionary history of this complex disorder? Digestive and Liver Disease, 36(10), 694-697. http://dx.doi.org/10.1016/j. dld.2004.05.010. PMid:15506671.

Schultz, M., Shin, S., \& Coppell, K. J. (2017). Awareness of coeliac disease among chefs and cooks depends on the level and place of training. Asia Pacific Journal of Clinical Nutrition, 26(4), 719-724. PMid:28582825.

Silvester, J. A., Weiten, D., Graff, L. A., Walker, J. R., \& Duerksen, D. R. (2016). Living gluten-free: Adherence, knowledge, lifestyle adaptations and feelings towards a gluten-free diet. Journal of Human Nutrition and Dietetics, 29(3), 374-382. http://dx.doi.org/10.1111/ jhn.12316. PMid:25891988.

Simpson, S., Lebwohl, B., Lewis, S. K., Tennyson, C. A., Sanders, D. S., \& Green, P. H. (2011). Awareness of gluten-related disorders: a survey of the general public, chefs and patients. e-SPEN, the European e-Journal of Clinical Nutrition and Metabolism, 6(5), 227-231. http:// dx.doi.org/10.1016/j.eclnm.2011.08.001.

Singh, J., \& Whelan, K. (2011). Limited availability and higher cost of gluten-free foods. Journal of Human Nutrition and Dietetics, 24(5), 479-486. http://dx.doi.org/10.1111/j.1365-277X.2011.01160.x. PMid:21605198.

Tomlin, J., Slater, H., Muganthan, T., Beattie, R. M., \& Afzal, N. A. (2015). Parental knowledge of coeliac disease. Informatics for Health \& Social Care, 40(3), 240-253. http://dx.doi.org/10.3109/17538157 .2014.907806. PMid:24786762.

Turkey. The Ministry of Health. (2019). Celiac disease control programme. Retrieved from https://hsgm.saglik.gov.tr/tr/metabolizma-ve-colyak/ çölyak-ve-görülme-sıklı̆̆ı.html

Zarkadas, M., Cranney, A., Case, S., Molloy, M., Switzer, C., Graham, I. D., Butzner, J. D., Rashid, M., Warren, R. E., \& Burrows, V. (2006). The impact of a gluten-free diet on adults with coeliac disease: results of a national survey. Journal of Human Nutrition and Dietetics, 19(1), 41-49. http://dx.doi.org/10.1111/j.1365-277X.2006.00659.x. PMid:16448474.

Zarkadas, M., Dubois, S., Macisaac, K., Cantin, I., Rashid, M., Roberts, K. C., La Vieille, S., Godefroy, S., \& Pulido, O. M. (2013). Living with coeliac disease and a gluten-free diet: a Canadian perspective. Journal of Human Nutrition and Dietetics, 26(1), 10-23. http://dx.doi.org/10.1111/j.1365-277X.2012.01288.x. PMid:23157646.

Zipser, R. D., Farid, M., Baisch, D., Patel, B., \& Patel, D. (2005). Physician awareness of celiac disease: a need for further education. Journal of General Internal Medicine, 20(7), 644-646. http://dx.doi.org/10.1007/ s11606-005-0111-7. PMid:16050861. 